\title{
O USO DOS RECURSOS NATURAIS E A UTILIZAÇÃO DE TRIBUTOS PARA SUA PROTEÇÃO: UM ESTUDO DE CASO EM PORTO SEGURO/BA
}

\author{
AUTOR: MARTA DE BARROS DOS SANTOS \\ CO-AUTOR/ORIENTADOR: ROBERTO MUHAJIR RAHNEMAY RABBANI
}

\begin{abstract}
Resumo: $O$ crescimento paulatino das agressões ao meio ambiente exige a atuação mais incisiva dos poderes públicos a fim preservar e garantir as futuras gerações o ambiente ecologicamente equilibrado, como prevê a Constituição Federal. E para tanto faz-se necessário a criação de instrumentos capazes de mitigar ações danosas ao meio ambiente, nesse contexto, como parte das políticas ambientais incentivadas em países desenvolvidos, sob o fundamento do princípio do poluidor-pagador, a tributação ambiental surge como um dos mecanismos de intervenção indireta do Estado, capaz de desmotivar a incidência negativa sobre o meio ambiente. Partindo deste pressuposto, o presente estudo analisou os fundamentos da tributação extrafiscal ambiental e de sua aplicabilidade no Brasil, verificando os fundamentos jurídicos que podem servir de base para a instituição destes tributos. A partir deste estudo inicial, pretende-se observar a viabilidade de se instituir um novo modelo integrado de intervenção estatal no meio ambiente na região de Porto Seguro/BA. Para, além disto, reconhecendo o instituto da taxa como um instrumento que pode ser utilizado com a finalidade de estimular a conservação ambiental foi realizado um breve estudo da taxa de visitação da Unidade de Conservação (UC) do Parque Nacional do Pau Brasil (PNPB), a fim de compreender qual tem sido a finalidade do valor arrecadado e como tem sido feita gestão desses recursos.
\end{abstract}

Palavras-chave: Tributação Ambiental, Extrafiscalidade e Responsabilidade Ambiental. 